\title{
Network models of minority opinion spreading
}

\author{
Javier Alvarez-Galvez \\ Department of Research Methodology and Communication Theory (Sociology IV), Complutense University \\ of Madrid. Campus de Somosaguas, 28223 Pozuelo de Alarcón - Madrid, SPAIN \\ Email: javalvar@ucm.es \\ Department of Social Science, Universidad Loyola Andalucía. Campus Palmas Altas, 41014 Sevilla, SPAIN \\ Email: jalvarez@uloyola.es
}

\begin{abstract}
Despite there are different models in literature that analyze the dynamic of opinion formation, less attention has been paid to explain how the structure of social networks and their contextual circumstances can influence the course of minority public opinions. This work is aimed to ask three basic questions: (1) how can affect the structure of social networks to minority opinion spreading, (2) how committed agents can influence in this process, and (3) how mass media action, as a contextual factor, can vary different agents' opinions and network composition. Agent-based modeling is used to perform a network model of preferential attachment that is used to explore how phenomena of minority opinion spreading can evolve under different simulated scenarios. This study shows that the success of minority opinions depends on the network structure and composition, and thus external factors such as mass media action that can mediate the strength of these internal determinants. In spite of people tend to remain silent when they feel that their opinions are in the minority pole, our findings suggest that prevailing majority opinion may be promptly replaced by formerly minority opinion if core agents in the network structure and/or external sources support this view.
\end{abstract}

\section{INTRODUCTION}

' HE shaping of public opinion through process of social interaction has been subject of significant interest in social sciences. At present, this topic has gained especial relevance due to the proliferation of online social media such as Twitter, Facebook or Youtube, and rising social movements related with the use of these platforms (e.g. Arab revolts, May 15th, Occupy Wall Street, etc.). Despite there are different models in literature that analyze the dynamic of opinion formation [1]-[11], less attention has been paid to explain how the structure of social networks and their contextual circumstances might affect the course of public opinions.

Previous studies demonstrate that physical factors such as network connectivity represents a crucial determinant of social contagion [12]. In terms of complex contagions, the diffusion of opinions needs two basic prerequisites: (1) a single contact between nodes; and (2) certain predisposition

This work was supported by the Complutense University of Madrid (Department of Research Methodology) and Universidad Loyola Andalucía (Seville). to acquire new information, either to (consciously or unconsciously) fill a gap of knowledge or reinforce previous beliefs. While the diffusion of information across social network, understood as a "simple communication process", only requires connectivity between nodes, the processes of opinion spreading requires multiple reinforcing ties to survive [12]. In real life, the success of a specific opinion depends on the connectivity between nodes and, obviously, on the social legitimacy of groups and their ideas in different normative contexts. In other words, the processes of opinion spreading are related to the consensus between social groups [13]-[15]. What opinions were socially allowed, what were prohibited or critiqued, what were successful or which failed in their attempt to spread depends on networks structure and a community consensus between majority and minority groups, where the latter are generally silenced [16].

In the field of political science and mass communication studies, the spiral of silence theory - propounded by Elisabeth Noelle-Neumann (1974) - tries to explain why minority opinions remain silent when society threatens individuals with fear of isolation [17]. Spiral of silence theory explains the opinion dynamics in terms of the assumption of dual climate of opinion: (1) individuals' interactions with mass media (i.e. indirect observation of reality through the eye of the media); and (2) reference social groups (i.e. direct or firsthand observation of reality). In this theory individuals are assumed to be active agents that are able to monitor the dual climate of opinion (mass media and public opinion), and intuitively compute the prevalence of opinions, to avoid being punished by the society for holding the minority opinion (and possibly controversial) [17]-[18]. Spiral of silence theory points out that individuals will fall silent if they consider their opinions are different from the dominating ideas of the mass media.

Thus the reinforcement of this dynamic leads to the progressive emergence of the spiral of silence phenomenon. Since this point of view, agents' individual reluctance to express their opinion, simply based on intuitive perceptions of what everyone else thinks, has important implications to explain the emergence of complex social dynamics at the macro level. Nevertheless, there are many debates and criticisms surrounding this theory. Different studies have 
found inconsistent results and methodological problems to articulate the aggregate-level (i.e. contextual variables) and individual-level (i.e. individual predictors related with agents' social behavior) [19]-[21].

Taking into account these previous findings from social sciences and computational physics, this work is aimed to study the process of minority opinion spreading under different possible scenarios, and giving response to three basic questions: (1) how can affect the structure of social networks to minority opinion spreading ('network physical structure' effect), (2) how committed agents can influence in this process ('opinion loyalty' effect), and (3) how mass media action, as a contextual factor, might vary agents' opinions and network composition ('media opinion' effect).

\section{METHOD}

Agent-based modeling (ABM) is used to perform a network model of preferential attachment that is used to explore how phenomena of minority opinion spreading can evolve under different simulated scenarios. The algorithm used in this simulation generates networks that are constructed through the process of "preferential attachment" in which agents, step by step, prefer to join to other agents who have many neighbors. This procedure leads to the emergence of clusters highly connected, while most agents in the network have very few connections.

This model simulates a scenario with two opinions (A-B) and four possible models of minority opinion spreading:

\section{A. Random model}

In this model, agents choose randomly one of their neighbors and adopt the respective neighbor's opinion. This is a model of "easy consensus", because agents have no previous knowledge and no preference. For example, this model could be possible in the case of conformity between communities that might choose between different unknown alternatives, and when the selection of alternatives have no important consequences.

\section{B. Learning-based model}

Agents listen their neighbors' opinions, adding arguments for the selection (i.e. weighting listened opinion), and update their probability of using one opinion (A) or the contrary (B). Agents' opinions might change over time: if (1) their neighbors have arguments to change their opinion and (2) they are not supposed to be committed with previous opinion.

\section{Threshold model}

Agents adopt one opinion if a certain percentage of their neighbors are already using this opinion. In this scenario, agents' opinion change depending on the proportion of neighbors that support the minority/majority opinion. That is, individual will modify his initial opinion (A) only if there are a fraction of neighbors holding other opinion (B). In this case, the process of opinion spreading is mainly affected by others' opinions. In this model, agents retain the new opinion one they have changed (i.e. cannot go back to the previous opinion).

\section{Media effects model}

Finally, agents adopt one opinion if a certain percentage of their neighbors and (observed) mass media are already using this opinion. In this model, agents' opinion change depending on the proportion of neighbors that support the minority/majority opinion, but also on the proportion of mass media sources in their context with opinion A or B. Therefore, individuals will change their initial opinions only if there are a fraction of neighbors and (listened) media sources holding other opinion.

In addition, other parameters such as average node degree and agents' commitment (i.e. loyal agents towards minority/majority opinion that do not change their initial state) (Fig. 1) have been introduced in the model to introduce more complexity and practicality in the initial conditions. Committed agents maintain their minority opinion when they listen majority opinion.

\section{RESULTS}

This study shows that the success of minority opinions does not only depends on the network structure and composition, but especially on external factors such as mass media information or agents' commitment that can mediate the strength of these structural determinants. In spite of people tend to remain silent when they feel that their opinions are in the minority pole, our findings suggest that prevailing majority opinion (A) may be replaced by formerly minority opinion (B) depending on different conditions.

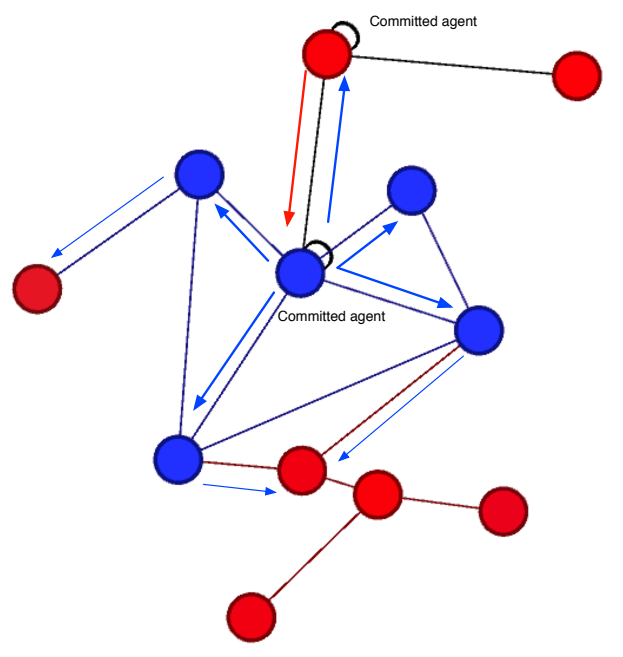

Fig. 1 Influence in committed agents

Table 1 shows that minority opinions (B, 10\%) are more probable to win the majority (A, 90\%) IF: (1) a certain proportion of loyal or committed agents in the network structure support the minority opinion (10\% committed); (2) there exist a high degree of connectivity between neighbors (i.e. nodes lives in a small-world); and/ or (3) when external 
sources (i.e. mass media information) give a higher external support to minority group.

Committed have been found critical in the model of individual random contagion. Despite is highly probable that minority opinion (10\% agents with opinion B) loses the game, this probability might be reversed if a minimum proportion of agents are loyal to opinion B. In addition, a higher connectivity between nodes increases exponentially the speed of opinion contagion in both situations (i.e. minority opinion wins or loses).

The learning-based model reduces highly the probability of success for minority opinion since this model is based on a summative criterion of listened opinions. In other words, we could say that majority group has a higher advantage to express and also be listened in the simulated world.

The minority opinion contagion based on the threshold model generally wins when the average-node-degree is high. In this model, agents embrace one opinion if a certain proportion of their neighbors are already using this opinion, so when the agents live in a small-world is highly probable they find other neighbors holding minority opinions. In this scenario, minority opinion can easily become the majority. On the other hand, the inclusion of committed agents seems to reinforce this tendency. That is, the opinion loyalty slightly increases the possibilities to locate additional B opinions that are susceptible to change A opinions.

Figure 2 shows twelve possible initializations in the threshold and media effect models: (a) average-node-degree 1 without committed agents; (b) average-node-degree 5 without committed agents; (c) average-node-degree 10 without committed agents; (d) average-node-degree 1 with $10 \%$ committed agents for $\mathrm{B}$; (e) average-node-degree 5 with $10 \%$ committed agents for B; and (f) average-nodedegree 10 with $10 \%$ committed agents for B. Despite the presence of a minimum proportion $(10 \%$ of agent holding minority opinion B) of committed agents does not produce important variations in the initial results, this effect might increase if the connectivity between nodes increases in the model.

Finally, the inclusion of media effect increases the general complexity of the initial model. In this case, agents listen both at neighbors and external media information (in case they are near to these sources) that randomly appear in the lattice. Media sources are defined in the model as motionless cellular automata that are situated in a second layer (i.e. as an environmental characteristic in the simulation). Media sources are more or less visible for the agents in the simulation depending on the agents' interest in listening to new information. The initial model with media effects included in the world 100 media sources and agents with visibility equal 2 (VSBT $=2$ patches). That is, agents are supposed to observe only adjacent media sources.

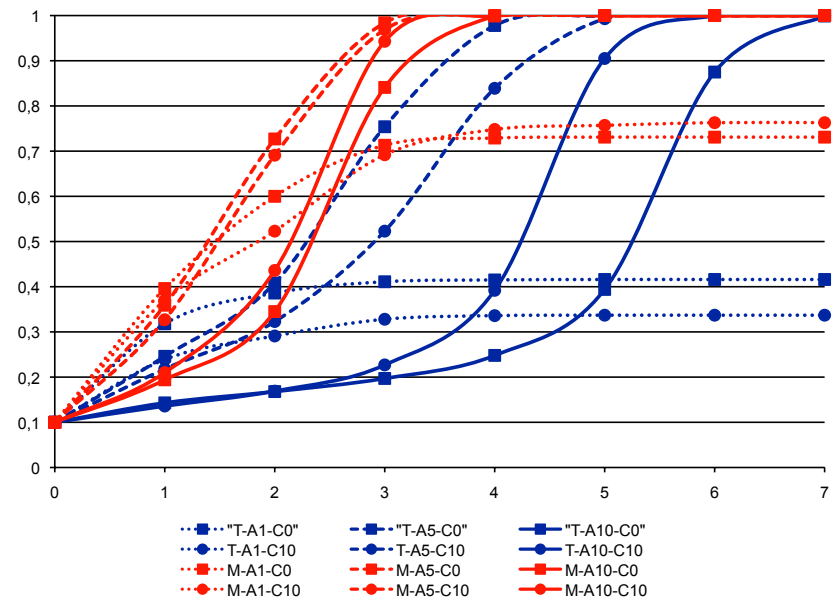

Fig. 2 Average node degree and committed agents (10\% B) effects (Threshold and Media Effect Models)

The inclusion of media effects $(30 \%$ for B) increases significantly the bias towards minority opinions, and varies the structural effect of the network and the position of (committed or non-committed) agents. These combined models demonstrate that the initial relevance of the network structure might be drastically reduced or even reinforced

TABLE I.

MODEL, INICIALIZATION CONDITIONS AND MAIN RESULTS

\begin{tabular}{|c|c|c|c|c|c|c|c|}
\hline $\begin{array}{c}\text { AB } \\
\text { Models }\end{array}$ & $\begin{array}{l}\text { Initialization } \\
\text { conditions }\end{array}$ & $\begin{array}{c}\text { Average- } \\
\text { node-degree } \\
\text { (AND) }\end{array}$ & $\begin{array}{l}\text { Commited- } \\
\text { agents }\end{array}$ & $\begin{array}{l}\text { Threshold, } \\
\text { (\% neighb.) }\end{array}$ & $\begin{array}{l}\text { Media effects } \\
\text { (\% bias B) }\end{array}$ & $\begin{array}{l}\text { Time for A } \\
\text { wins with } \\
\text { AND 1-10 }\end{array}$ & $\begin{array}{l}\text { Time for B } \\
\text { wins with } \\
\text { AND 1-10 }\end{array}$ \\
\hline \multirow[t]{2}{*}{ Random } & $\begin{array}{l}1000 \text { nodes; } 10 \% \\
\text { opinion B, } 90 \% \text { A }\end{array}$ & $1-5-10$ & No & No & No & $495-126-100$ & B loses \\
\hline & $\begin{array}{l}1000 \text { nodes; } 10 \% \\
\text { opinion B, } 90 \% \text { A }\end{array}$ & $1-5-10$ & $10 \%$ of $\mathrm{Bs}$ & No & No & A loses & $971-395-159$ \\
\hline \multirow[t]{2}{*}{$\begin{array}{l}\text { Learning- } \\
\text { based }\end{array}$} & $\begin{array}{l}1000 \text { nodes; } 10 \% \\
\text { opinion B, } 90 \% \text { A }\end{array}$ & $1-5-10$ & No & No & No & $395-126-98$ & B loses \\
\hline & $\begin{array}{l}1000 \text { nodes; } 10 \% \\
\text { opinion } \mathrm{B}, 90 \% \mathrm{~A}\end{array}$ & $1-5-10$ & $10 \%$ of $\mathrm{Bs}$ & No & No & $620-159-118$ & B loses \\
\hline \multirow[t]{2}{*}{ Threshold } & $\begin{array}{l}1000 \text { nodes; } 10 \% \\
\text { opinion B, } 90 \% \text { A }\end{array}$ & $1-5-10$ & No & $30 \%$ & No & 4-loses-loses & $3[33 \%]-5-7$ \\
\hline & $\begin{array}{r}1000 \text { nodes; } 10 \% \\
\text { opinion } \mathrm{B}, 90 \% \mathrm{~A} \\
\end{array}$ & $1-5-10$ & $10 \%$ of $\mathrm{Bs}$ & $30 \%$ & No & 3-loses-loses & $3[37 \%]-4-5$ \\
\hline \multirow[t]{2}{*}{$\begin{array}{l}\text { Media } \\
\text { effect }\end{array}$} & $\begin{array}{l}\text { Equal conditions } \\
+100 \text { media sour. }\end{array}$ & $1-5-10$ & No & $30 \%$ & $\begin{array}{c}100 \text { media, } \\
30 \%(\mathrm{vsbt}=2)\end{array}$ & $\begin{array}{c}2[14 \%]-\text { loses- } \\
\text { loses }\end{array}$ & $4-3-2$ \\
\hline & $\begin{array}{l}\text { Equal conditions } \\
+100 \text { media sour. }\end{array}$ & $1-5-10$ & $10 \%$ of Bs & $30 \%$ & $\begin{array}{c}100 \text { media, } \\
30 \%(\mathrm{vsbt}=2)\end{array}$ & $\begin{array}{c}2[11 \%]-\text { loses- } \\
\text { loses }\end{array}$ & $3-2-2$ \\
\hline
\end{tabular}


with the presence of other communication channels.

Figure 3 compares results for the threshold and the media effects models. This figure demonstrates that external (media) information might produce important changes in the outcome models, independently of the presence of committed agents and the degree of connectivity between agents.

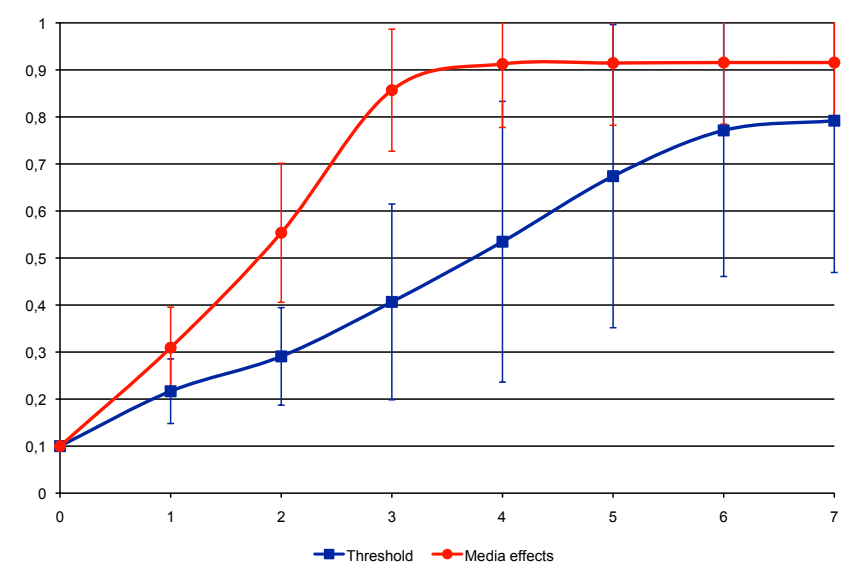

Fig. 3 Models with confidence interval (threshold and media effect)

\section{CONCLUSSION}

The present work shows how different network models that are theoretically based on different opinion types might produce extremely different results. Random contagion models could be based on conformity mechanism due to the lack of initial information and predisposition towards certain opinion, while learning or threshold models implies social choice based on different known alternatives and also on neighbors' opinions and expectations for what should be considered the appropriate public behavior. The inclusion of media effects introduce external information in the world and produce a simulation that could be initially more realistic, and also more complex to predict (especially because this effect can modify the impact of global connectivity).

Of course, we know mass media can modify our opinion, attitudes, and social behavior, especially under certain contextual circumstances when social agents have no firsthand information to choose their alternatives [22]-[23]. In these cases where agents do not obtain information from their network and they have to look for additional data in the media, as a result media effects could become stronger in this situation. Clearly, outcomes are hardly predictable when agents receive information both from two channels (i.e. social networks and media), however, we could adjust our prediction if certain communication channel present more relevance in the results under specific contexts.

The results of the present model for the study of minority opinion spreading might be relevant to understand the communication process involved in formation of public opinion, social contagion dynamics, and the emergence of collective behavior in complex social systems. The model also may apply to study of rumor propagation through social networks and opinion silencing processes.

This is a basic model with two competing opinions that has been performed to study the fundamental conditions for minority opinion propagation in small-world and free-scale networks, but future models should include additional opinions, and also could include inoculation effects (i.e. resistance to persuasion) that could make it difficult the process of social contagion.

\section{REFERENCES}

[1] W. Weidlich, Sociodynamics - A systematic approach to mathematical modeling in social sciences, Taylor \& Francis, London (2002).

[2] S. Galam, J.D. Zucker, "From individual choice to group decisionmaking", Physica A 287, 644 (2000).

[3] S. Galam, B. Chopard, A. Masselot, M. Droz, "Competing spices dynamics: qualitative advantage versus geography", Eur. Phys. J. B 4, 529 (1998).

[4] S. Galam, "Minority opinion spreading in random geometry". Eur. Phys. J. B 25, 403-406 (2002).

[5] S. Galam, Modelling rumors: the no plane Pentagon French hoax case", Physica A 320, 571 (2003).

[6] Galam S. Sociophysics: A Physicist's Modeling of Psycho-political Phenomena (Cambridge University Press, 2012).

[7] G. Deffuant, D. Neau, F. Amblard, G. Weisbuch, "Mixing beliefs among interacting agents" Complex Syst. 3, 87 (2000);

[8] R. Hegselmann, U. Krausse, "Opinion dynamics and bounded confidence: models, analysis and simulation" J. Artif. Soc. Social Sim. 5,3 (2002).

[9] S.W. Wang, C.Y. Huang, C.T. Sun, "Modeling self-perception agents in an opinion dynamics propagation society", Simulation 90, 3, 238248 (2014).

[10] K. Sznajd-Weron, J. Sznajd, "Opinion evolution in closed community" Int. J. Mod. Phys. C 11, 1157 (2000); K. Sznajd-Weron, Phys. Rev. E 66, 046131 (2002); K. Sznajd-Weron, J. Sznajd, Int. J. Mod. Phys. C 13, 115 (2000)

[11] D. Stauffer "How to convince others? Monte Carlo simulations of the Sznajd model", AIP Conference Proceedings on the Monte Carlo method in the physical sciences, jul. 2003.

[12] D. Centola, "Failure in Complex Social Networks", Journal of Mathematical Sociology, 33:64-68, 2009.

[13] D. Centola, Eguiluz, V., \& Macy, M., "Cascade dynamics of complex propagation". Physica A, 374, 449-456, 2007.

[14] D. Centola \& Macy, M. "Complex contagions and weakness of long ties". Am. J. Soc., 113(3), 702-734, 2007.

[15] C.J. Tessone, R. Toral, P. Amengual, H.S. Wio, and M. San Miguel, "Neighborhood models of minority opinion spreading", Eur. Phys. J. B 39, 535-544 (2004).

[16] A. Pentland, Social Physics: How Good Ideas Spread-The Lessons from a New Science, Penguin Press, 2014.

[17] E. Noelle-Neumann, The Spiral of Silence: A Theory of Public Opinion. Journal of communication, 24(2), 43-51, 1974.

[18] E. Noelle-Neumann, The spiral of silence: public opinion-our social skin (2nd ed.). Chicago: University of Chicago Press, 1993.

[19] D. Scheufle and P. Moy, "Twenty-five years of the spiral of silence: A conceptual review and empirical outlook". International Journal of Public Opinion Research, 12(1), 3, 2000.

[20] W. Donsbach and M. Traugott, The SAGE handbook of public opinion research: Sage Publications Ltd., 2007.

[21] C. Glynn, A. Hayes, and J. Shanahan, "Perceived support for one's opinions and willingness to speak Out: A meta-analysis of survey studies on the'spiral of silence". Public opinion quarterly, 61(3), 452, 1997.

[22] S. Ball-Rokeach, "A Theory of Media Power and a Theory of Media Use: Different Stories, Questions, and Ways of Thinking". Mass Communication \& Society, 1: 5-40, 1998.

[23] M. De Fleur and S. Ball-Rokeach, Fundamentals of Human Communication. San Francisco: Mayfield Publishing Company, 1993 